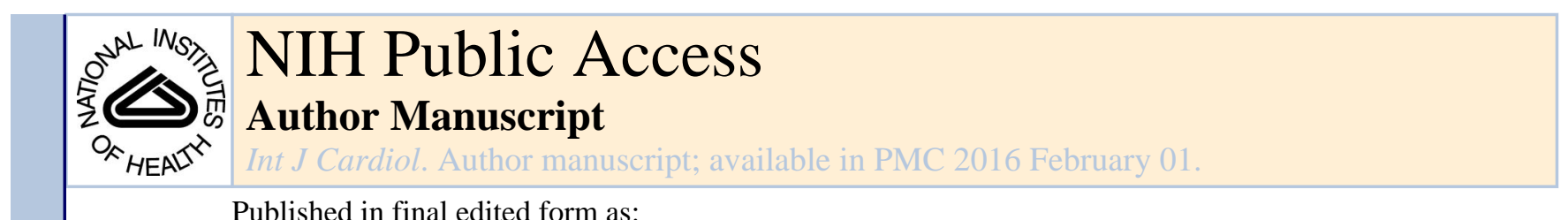

Published in final edited form as:

Int J Cardiol. 2015 February 1; 180: 228-236. doi:10.1016/j.ijcard.2014.11.119.

\title{
Short-Coupled Polymorphic Ventricular Tachycardia At Rest Linked to a Novel Ryanodine Receptor (RyR2) Mutation: Leaky RyR2 Channels Under Non-Stress Conditions
}

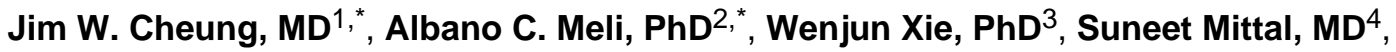 \\ Steven Reiken, $\mathrm{PhD}^{5}$, Anetta Wronska, $\mathrm{MSc}^{6}$, Linna Xu, MBBS ${ }^{7}$, Jonathan S. Steinberg, \\ MD $^{8}$, Steven M. Markowitz, MD ${ }^{9}$, Sei Iwai, MD ${ }^{10}$, Alain Lacampagne, PhD², Bruce B. \\ Lerman, MD ${ }^{11}$, and Andrew R. Marks, MD ${ }^{12}$ \\ ${ }^{1}$ Division of Cardiology, Weill Cornell Medical College, New York, NY. This author takes \\ responsibility for all aspects of the reliability and freedom from bias of the data presented and \\ their discussed interpretation. \\ ${ }^{2}$ Inserm U1046, University of Montpellier I, Montpellier, France and Department of Physiology and \\ Cellular Biophysics and the Clyde and Helen Wu Center for Molecular Cardiology, Columbia \\ University College of Physicians and Surgeons, New York, NY. This author takes responsibility \\ for all aspects of the reliability and freedom from bias of the data presented and their discussed \\ interpretation.
}

${ }^{3}$ Department of Physiology and Cellular Biophysics and the Clyde and Helen Wu Center for Molecular Cardiology, Columbia University College of Physicians and Surgeons, New York, NY. This author takes responsibility for all aspects of the reliability and freedom from bias of the data presented and their discussed interpretation.

${ }^{4}$ Valley Health System, Ridgewood, NJ. This author takes responsibility for all aspects of the reliability and freedom from bias of the data presented and their discussed interpretation.

${ }^{5}$ Department of Physiology and Cellular Biophysics and the Clyde and Helen Wu Center for Molecular Cardiology, Columbia University College of Physicians and Surgeons, New York, NY. This author takes responsibility for all aspects of the reliability and freedom from bias of the data presented and their discussed interpretation.

${ }^{6}$ Department of Physiology and Cellular Biophysics and the Clyde and Helen Wu Center for Molecular Cardiology, Columbia University College of Physicians and Surgeons, New York, NY. This author takes responsibility for all aspects of the reliability and freedom from bias of the data presented and their discussed interpretation.

(c) 2014 Elsevier Ireland Ltd. All rights reserved.

Address for correspondence: Jim W. Cheung, MD, Division of Cardiology, Weill Cornell Medical College, 520 East $70^{\text {th }}$ Street, Starr 4, New York, NY 10021, Tel: 212-746-2158, Fax: 212-746-6951, jac9029@med.cornell.edu.

These authors contributed equally to this work.

Publisher's Disclaimer: This is a PDF file of an unedited manuscript that has been accepted for publication. As a service to our customers we are providing this early version of the manuscript. The manuscript will undergo copyediting, typesetting, and review of the resulting proof before it is published in its final citable form. Please note that during the production process errors may be discovered which could affect the content, and all legal disclaimers that apply to the journal pertain.

Conflicts of Interest: Dr. Andrew R. Marks is a consultant for ARMGO Pharma, Inc. a biotechnology company targeting RyR2 treatment for prevention of CPVT. The other authors have no relevant conflicts. 
${ }^{7}$ Division of Cardiology, Weill Cornell Medical College, New York, NY. This author takes responsibility for all aspects of the reliability and freedom from bias of the data presented and their discussed interpretation.

${ }^{8}$ Valley Health System, Ridgewood, NJ. This author takes responsibility for all aspects of the reliability and freedom from bias of the data presented and their discussed interpretation.

${ }^{9}$ Division of Cardiology, Weill Cornell Medical College, New York, NY. This author takes responsibility for all aspects of the reliability and freedom from bias of the data presented and their discussed interpretation.

${ }^{10}$ Westchester Medical Center, Valhalla, NY. This author takes responsibility for all aspects of the reliability and freedom from bias of the data presented and their discussed interpretation.

${ }^{11}$ Division of Cardiology, Weill Cornell Medical College, New York, NY. This author takes responsibility for all aspects of the reliability and freedom from bias of the data presented and their discussed interpretation.

${ }^{12}$ Department of Physiology and Cellular Biophysics and the Clyde and Helen Wu Center for Molecular Cardiology, Columbia University College of Physicians and Surgeons, New York, NY. This author takes responsibility for all aspects of the reliability and freedom from bias of the data presented and their discussed interpretation.

\section{Abstract}

Background-Ryanodine receptor (RyR2) mutations have largely been associated with catecholaminergic polymorphic ventricular tachycardia (PMVT). The role of RyR2 mutations in the pathogenesis of arrhythmias and syncope at rest is unknown. We sought to characterize the clinical and functional characteristics associated with a novel RyR2 mutation found in a mother and daughter with PMVT at rest.

Methods and Results-A 31-year-old female with syncope at rest and recurrent short-coupled premature ventricular contractions (PVCs) initiating PMVT was found to be heterozygous for a novel RyR2-H29D mutation. Her mother, who also had syncope at rest and short-coupled PMVT, was found to harbor the same mutation. Human RyR2-H29D mutant channels were generated using site-directed mutagenesis and heterologously expressed in HEK293 cells together with the stabilizing protein calstabin2 (FKPB12.6). Single channel measurements of RyR2-H29D mutant channels and wild type (WT) RyR2 channels were compared at varying concentrations of cytosolic $\mathrm{Ca}^{2+}$. Binding affinities of the RyR2-H29D channels and RyR2-WT channels to calstabin2 were compared. Functional characterization of the RyR2-H29D mutant channel revealed significantly higher open probability and opening frequency at diastolic levels of cytosolic $\mathrm{Ca}^{2+}$ under non-stress conditions without protein kinase A treatment. This was associated with a modest depletion of calstabin 2 binding under resting conditions.

Conclusions-The RyR2-H29D mutation is associated with a clinical phenotype of shortcoupled PMVT at rest. In contrast to catecholaminergic PMVT-associated RyR2 mutations, RyR2-H29D causes a leaky channel at diastolic levels of $\mathrm{Ca}^{2+}$ under non-stress conditions. Leaky RyR2 may be an under-recognized mechanism for idiopathic PMVT at rest. 


\section{Keywords}

ryanodine receptor; syncope; polymorphic ventricular tachycardia; genetics

\section{Introduction}

Polymorphic ventricular tachycardia (PMVT) and ventricular fibrillation (VF) in patients without structural heart disease may account for up to $8 \%$ of sudden cardiac death cases ${ }^{1}$. Primary electrophysiological diseases that have been linked to PMVT and VF in patients with structurally normal hearts include: short and long QT syndrome, Brugada syndrome, early repolarization syndrome, catecholaminergic PMVT (CPVT), idiopathic VF and shortcoupled torsade de pointes (SC-TdP). ${ }^{2,3,4,5,6,7}$. In particular, ryanodine receptor (RyR2) mutations have been associated with CPVT, which is characterized by exercise-induced arrhythmias. ${ }^{5}$ The role of RyR2 mutations in the pathogenesis of PMVT and VF at rest in patients with structurally normal hearts is unclear.

Here, we report a novel mutation in the cardiac ryanodine receptor (RyR2) gene found in a mother and daughter who had identical presentations of syncope at rest and short-coupled PMVT. After identification of the RyR2 mutation (RyR2-H29D) shared by both patients, we sought to characterize the functional and biochemical consequences of this single amino acid substitution.

\section{Materials and Methods}

\section{Clinical characterization}

We obtained a complete medical history with emphasis on syncope, near syncope and palpitations in all family members included in this study. Information from echocardiography studies, Holter and event monitors, hospital telemetry, and electrophysiology studies were recorded. Treadmill stress tests were performed using the Cornell protocol ${ }^{8}$. Written informed consent was obtained from family members who agreed to have blood samples obtained for genetic evaluation. This study was approved by the Cornell Institutional Review Board.

\section{Mutation screening}

Genomic DNA was extracted from peripheral blood lymphocytes using standard methods ${ }^{9}$. The RyR 2 coding regions were amplified using polymerase chain reaction and analyzed by denaturing high-performance liquid chromatography.

\section{Functional and biochemical characterization of mutant RyR2 channels}

Recombinant mutant channels were generated and expressed in HEK293 cells. The hRyR2H29D recombinant construct was generated using QuikChange II XL Site-Directed Mutagenesis Kit (Stratagene). Single channel measurements were performed to compare RyR2-WT and RyR2-H29D channel properties in planar lipid bilayers. Measurements of calstabin2 binding to immunoprecipitated RyR2-WT and RyR2-H29D channels were performed. A detailed Methods section can be found in the Supplementary Materials. 


\section{Results}

\section{Clinical phenotype}

The proband (III-3 in Figure 1A) is a 31-year old Indian female who presented to Weill Cornell Medical Center with syncope. While sitting at her desk at work, she had sudden loss of consciousness. She did not recall experiencing any emotional stress prior to the event. She went home and had another episode of syncope at rest. Upon awakening, she called for an emergency medical team. On arrival to the hospital, her ECG revealed sinus rhythm with frequent PVCs (Figure 2A). Mild early repolarization changes in the inferolateral leads and changes in $\mathrm{V}_{2}$ that were non-diagnostic for Brugada syndrome were seen. There was no evidence of an abnormal QT interval or signs of arrhythmogenic right ventricular cardiomyopathy. Echocardiography was normal. On telemetry, she had episodes of nonsustained PMVT that were initiated with unifocal PVCs with short coupling intervals of 220 - $260 \mathrm{~ms}$ (Figure 2B). She was placed on verapamil, but her short-coupled PVCs persisted.

She underwent an electrophysiological study where two PVC morphologies were observedboth with left bundle branch block, left superior axis morphology. The patient was not inducible for ventricular tachycardia or VF with rapid ventricular pacing or up to triple ventricular extrastimuli. Infusion of isoproterenol had no effect on PVC frequency. The two PVCs were mapped to the basal free wall of the right ventricle and ablated. A treadmill exercise test performed after the ablation revealed no PVCs, VT or ischemic changes during exercise. The patient underwent ICD implantation due to concerns for recurrent arrhythmias.

During > 7 years of follow-up, the patient had 22 episodes of non-sustained PMVT but no ICD therapies for sustained PMVT. Genetic testing (Familion, New Haven, CT) was performed in 2010. The patient was found to be heterozygous for a RyR2-H29D (85 C>G) mutation, which was not seen in a control population of 400 patients. In addition, this RyR2 variant was not present in the Single Nucleotide Polymorphism (dbSNP), 1000 Genomes, or NHLBI Exome Sequencing Project (ESP) databases. Screening for pathogenic mutations for long QT syndrome, Brugada syndrome and early repolarization syndrome (Familion, New Haven, CT) was also negative. Full sequence analysis of RyR2 gene exons was performed and the presence of the RyR2-H29D mutation was confirmed with no other mutations detected elsewhere (Figure 1B).

The proband's mother (II-2 in Figure 1A) presented in June 1979 at the age of 41 with palpitations and light headedness. Her baseline ECG revealed borderline J point elevation in the inferior leads (Figure 3A). She was noted on monitoring to have ventricular bigeminy and was placed on procainamide. However, she had recurrent syncope at rest. In one episode, the patient experienced syncope while sitting in bed talking to her children. On November 1979, she had an episode of syncope at work and was brought to the hospital. She was found to be in ventricular bigeminy with very short coupling intervals (200 ms) leading to sustained PMVT (Figure 3B). Cardiac catheterization revealed normal coronary arteries. Control of sustained ventricular arrhythmias was achieved with procainamide and quinidine but due to side effects, she was switched to sotalol. She presented in 2007 with symptomatic sinus bradycardia and a dual chamber pacemaker was implanted. Review of pacemaker diagnostics over $>5$ years of follow-up revealed no sustained arrhythmias. A genetic screen 
for the RyR2-H29D mutation in this patient was positive. The patient had a history of gastric cancer and died at the age of 74 of non-cardiac reasons. In both the proband and the proband's mother's cases, cardiac MRI scans were not performed prior to cardiac device implantation. Neither patient was ever found to have signs of arrhythmogenic right ventricular cardiomyopathy by echocardiographic or ECG surveillance over long term follow-up.

The proband's sister (III-1 in Figure 1A) had a history of syncope without prodrome while opening a door to her home. She had a history of palpitations for several years. She had a normal ECG, echocardiogram and negative treadmill study. A 14-day mobile cardiac outpatient telemetry monitor revealed symptomatic ventricular couplet with a coupling interval of $380 \mathrm{~ms}$ but no VT. A genetic screen for the RyR2-H29D mutation in this patient was positive. The proband's brother (III-2 in Figure 1A) had a remote history of two episodes of syncope as a teenager associated with dizziness and diaphoresis while standing which was felt to be consistent with vasovagal syncope. He denied any history of palpitations. He had a normal ECG, echocardiogram and treadmill study. A 24-hour Holter monitor revealed no ventricular ectopy. His screen for the RyR2-H29D mutation was negative (Figure 1C). Analysis of RyR2 sequence alignment indicates that the RyR2-H29D mutation is near the amino terminal hot-spot region of RyR2 (Figure 1D).

\section{Functional characterization of short coupled TdP-linked RyR2 mutation}

In CPVT, single-point mutations in RyR2 can alter the biophysical properties of RyR2 channel, in particular its sensitivity to activation by cytosolic $\mathrm{Ca}^{2+}$ under conditions of PKA phosphorylation ${ }^{10-13}$. Since our patients did not have a CPVT phenotype given their arrhythmias and syncope at rest, we postulated that the RyR2-H29D mutation alters RyR2 function under resting conditions. To evaluate the functional consequences of the RyR2H29D mutation, we examined its single-channel properties in presence of calstabin2 and compared them to the RyR2-WT channels using a planar lipid bilayer model. Over a range of cytosolic (cis) $\mathrm{Ca}^{2+}$ concentrations from $150 \mathrm{nmol} / \mathrm{L}$ (diastolic level) up to $10 \mu \mathrm{mol} / \mathrm{L}$ (systolic level), we evaluated the single-channel open probability, mean open and close times, and frequency of openings.

Under basal conditions with no PKA phosphorylation and at diastolic cytosolic $\mathrm{Ca}^{2+}$ concentrations of $150 \mathrm{nmol} / \mathrm{L}$, RyR2-H29D mutant channels exhibited a significantly higher open probability $(\mathrm{Po})$ when compared to WT channels (mean Po of $0.071 \pm$ S.E.M. of 0.017 $(n=9)$ for RyR2-H29D vs, mean Po of $0.009 \pm 0.001(n=5)$ for RyR2-WT; $p=0.021$; Figures 4A-B and 5A). While the mean open times (To) and close times (Tc) were similar (Online Figure 1), the frequency of opening (Fo) was significantly higher at $150 \mathrm{nmol} / \mathrm{L}$ in RyR2-H29D channels than when compared to RyR2-WT channels (mean Fo of $7551 \pm 1549$ events/min $(n=8)$ for RyR2-H29D vs. mean Fo of $988 \pm 139$ events/min $(n=5)$ for RyR2WT, $\mathrm{p}=0.007$; Figures $4 \mathrm{~A}-\mathrm{B}$ and $5 \mathrm{~B}$ ). Similarly, at cytosolic $\mathrm{Ca}^{2+}$ concentrations of 350 nmol/L, RyR2-H29D mutant channels exhibited a significantly higher Po (mean Po of 0.074 $\pm 0.019(\mathrm{n}=9)$ for RyR2-H29D vs. mean Po of $0.017 \pm 0.005(\mathrm{n}=5)$ for RyR2-WT, $\mathrm{p}=$ 0.047; Figure 4A-B and 5A) as well as a significantly higher Fo than that of WT channels (mean Fo of $7179 \pm 1380$ events/min $(n=8)$ for RyR2-H29D, versus mean Fo of $1857 \pm$ 
587 events/min $(\mathrm{n}=5)$ for RyR2-WT, $\mathrm{p}=0.014$; Figures 4A-B and 5B). A significantly higher Po was still observed under higher cytosolic $\mathrm{Ca}^{2+}$ levels of $700 \mathrm{nmol} / \mathrm{L}$ for RyR2H29D mutant channels (Figure 5A), as well as a trend towards higher Fo (Figure 5B). Of note, neither To nor Tc were changed at $350 \mathrm{nmol} / \mathrm{L}$ and $700 \mathrm{nmol} / \mathrm{L}$ (Online Figure 1). Normalized single-channel Po of RyR2-H29D mutant channels was $>40 \%$ maximal Po at low cytosolic $\mathrm{Ca}^{2+}(150$ and $350 \mathrm{nmol} / \mathrm{L})$, which was significantly higher than the normalized single-channel Po of WT channels (normalized Po at $150 \mathrm{nmol} / \mathrm{L}$ of $0.435 \pm$ $0.085(\mathrm{n}=8)$ for RyR2-H29D vs. mean Po of $0.149 \pm 0.055(\mathrm{n}=5)$ for RyR2-WT, $\mathrm{p}=$ 0.034; and normalized Po at $350 \mathrm{nmol} / \mathrm{L}$ of $0.435 \pm 0.076(\mathrm{n}=8)$ for RyR2-H29D vs. mean Po of $0.179 \pm 0.076(n=5)$ for RyR2-WT, $p=0.047$; Figure 5C).

Because single-point RyR2 mutations have been associated to ARVD and CPVT disorders, we also measured the electrophysiological properties of RyR2-H29D channels under in vitro PKA phosphorylation and compared them to PKA-phosphorylated RyR2-WT channel properties. Under stress conditions, at diastolic cytosolic $\mathrm{Ca}^{2+}$ concentrations of $150 \mathrm{nmol} / \mathrm{L}$, RyR2-H29D mutant channels exhibited a significantly higher Po when compared to WT channels (mean Po of $0.341 \pm$ S.E.M. of $0.108(\mathrm{n}=6)$ for RyR2-H29D vs, mean Po of 0.092 $\pm 0.047(\mathrm{n}=7)$ for RyR2-WT; $\mathrm{p}=0.022$; Online Figure 2 ). Fo was significantly higher at $150 \mathrm{nmol} / \mathrm{L}$ in RyR2-H29D channels than when compared to RyR2-WT channels (mean Fo of $5268 \pm 1342$ events/min $(n=6)$ for RyR2-H29D vs. mean Fo of $2151 \pm 1969$ events/min $(\mathrm{n}=7)$ for RyR2-WT, $\mathrm{p}=0.035$; Online Figure 2). At 350 and $700 \mathrm{nmol} / \mathrm{L}$, no difference in Po and Fo was found (Online Figure 2). No difference was found in To and Tc at 150, 350 and $700 \mathrm{nmol} / \mathrm{L}$ (data not shown).

\section{Biochemical characterization of RyR2-H29D mutation}

It has been previously shown that depletion of calstabin 2 from the RyR 2 channel complex destabilizes the closed state of RyR2, resulting in an increased sensitivity to low cytosolic $\mathrm{Ca}^{2+}$ and a leaky channel ${ }^{13-18}$. Recombinant CPVT-related RyR2 mutant channels expressed in HEK293 cells exhibit a reduced affinity for calstabin2 compared to WT channels in stress-related conditions ${ }^{11,13,14}$. To determine whether the increased Po and Fo observed for the RyR2-H29D mutant channels are associated with depletion of the stabilizing subunit calstabin 2 protein under basal conditions, RyR2 macromolecular complexes were immunoprecipitated from HEK293 ER vesicles in a non-PKA phosphorylated and reduced state. We observed a significant, albeit modest, reduction in the amount of calstabin2 bound to the RyR2-H29D macromolecular complex when compared to the RyR2-WT channel ( $p=0.021$; Figure 6A-B).

We then assessed the effect of in vitro PKA phosphorylation on the RyR2 macromolecular complexes. We found that stress conditions exacerbate the depletion of calstabin 2 from both RyR2-H29D and RyR2-WT macromolecular complexes (Online 3A-B). There was no significant difference in the degree of calstabin 2 depletion associated with PKA phosphorylated RyR2-H29D compared to PKA phosphorylated RyR2-WT ( $p=0.207, n=4)$ (Online Figure 3B). There was no difference in the level of PKA phosphorylation found between RyR2-H29D and RyR2-WT (Online Figure 3C) nor in RyR2 protein expression 
between the RyR2-WT and H29D mutant and respective amounts of calstabin2 expressed in isolated ER microsomes (Online Figure 3D).

\section{Discussion}

In this study, we demonstrate that a novel single point mutation in the ryanodine receptor, RyR2-H29D, is associated with PMVT at rest. The two affected patients harboring the RyR2-H29D mutation exhibited syncope at rest and short-coupled PVCs inducing PMVT. Unlike typical CPVT-associated RyR2 mutations where mutant RyR2 channels become leaky occur only under stress conditions, we identified increased Po and Fo properties of the RyR2-H29D channel at low diastolic levels of cytosolic $\mathrm{Ca}^{2+}$ in a non-PKA phosphorylated state.

\section{Clinical consequences of the RyR2-H29D mutation}

RyR mutations in patients with structurally normal hearts and cardiac arrhythmias have previously mainly been linked to $\mathrm{CPVT}^{6}$. Patients with CPVT typically present with exertional syncope and salvos of bidirectional or PMVT ${ }^{19}$. In our study, both affected patients had arrhythmias at rest. Our proband did not have exercise-induced arrhythmias during stress testing, although this was performed after PVC ablation. Our two affected patients with the RyR2-H29D mutation had tightly coupled PVCs with coupling intervals of $200-300 \mathrm{~ms}$. Their clinical presentations are similar to those that have been described for patients with short-coupled torsade de pointes. In the original series of these patients by Leenhardt et al. ${ }^{7}$, PVCs with coupling intervals of $240 \mathrm{~ms}-300 \mathrm{~ms}$ were found to initiate torsade de pointes at rest.

The phenomenon of PVC-initiation of PMVT has been described for primary electrophysiological disorders such as long QT syndrome, Brugada syndrome and idiopathic VF. Catheter ablation of PVCs as adjunctive therapy in the treatment of these patients has been described ${ }^{20,21}$. The efficacy of point ablations in reducing arrhythmia recurrence in patients with ion channelopathies may suggest a predilection for PVC triggers to occur at specific ventricular sites despite the presence of germline mutations that affect all cardiomyocytes. One other group has described catheter ablation of multifocal PVCs initiating PMVT/VF due to a RyR2 mutation, although in that case, the patient had $\mathrm{CPVT}^{22}$.

Of note, one subject, the sister of the proband, had the RyR2-H29D mutation but did not have documented PMVT. She had a history of syncope and palpitations but only had one symptomatic ventricular couplet detected on mobile cardiac telemetry. It is unclear if the patient's syncope was due to undiagnosed PMVT or some other etiology. This may reflect variable penetrance of the RyR2-H29D mutation.

\section{Functional and biochemical properties of the RyR2-H29D mutant channel}

Using the planar lipid bilayer technique, we measured RyR2 single channels and demonstrated that the RyR2-H29D mutation confers increased Po and Fo in response to low diastolic levels of cytosolic $\mathrm{Ca}^{2+}$ in a non-PKA phosphorylated state. A proposed schematic model of the pathophysiology behind RyR2-H29D-associated arrhythmogenesis is shown in Figure 7. Increased SR $\mathrm{Ca}^{2+}$ leak at rest via the RyR2-H29D channel may lead to increased 
cytosolic $\mathrm{Ca}^{2+}$ levels which in turn could activate the $\mathrm{Na}^{+} / \mathrm{Ca}^{2+}$ exchanger (NCX) to generate a transient inward current and produce delayed afterdepolarizations that trigger short-coupled PVCs and PMVT ${ }^{23,}{ }^{24}$. Cytosolic $\mathrm{Ca}^{2+}$ concentration-dependent NCX activation may also give rise to early afterdepolarizations ${ }^{25}$. Moreover, the potassium inward rectifier current $\mathrm{I}_{\mathrm{K} 1}$ (KCNJ2) may be inhibited, leading to destabilization of the resting membrane potential with greater $\mathrm{NCX}$ current and afterdepolarizations ${ }^{26}$. We also found decreased binding of calstabin2 to the mutant RyR2-H29D channel in the basal state. The magnitude of the decrease in affinity of calstabin2 to the RyR2-H29D mutation was modest albeit statistically significant in the baseline state. The difference in calstabin2 depletion between mutant RyR2-H29D and wildtype RyR2 was not statistically significant under PKA phosphorylation conditions. Hence, the overall functional consequence of altered calstabin2 -mutant RyR2-H29D binding is unclear.

Increased Po and Fo at low levels of cytosolic $\mathrm{Ca}^{2+}$ without PKA phosphorylation distinguishes the RyR2-H29D mutation from CPVT-linked mutations. Under PKA phosphorylation conditions, the RyR2-H29D also exhibited channel leak at diastolic cytosolic calcium concentrations, suggesting that RyR2-H29D may lead to arrhythmias both at rest and with exertion. Previously described CPVT-associated RyR2 mutants including RyR2-G230C, RyR2-S2226L, RyR2-P2328S, RyR2-R2474S, RyR2-Q4201R, RyR2R4497C and RyR2-V4653F have altered channel activity at low cytosolic levels of $\mathrm{Ca}^{2+}$ but only with PKA phosphorylation ${ }^{10,13,11}$. The RyR2-S4565R mutation, which has been linked to sudden infant death syndrome, has been associated with increased sensitivity to cytosolic $\mathrm{Ca}^{2+}$ under basal conditions without PKA treatment. ${ }^{12}$ Its alteration in channel activity was seen at cytosolic $\mathrm{Ca}^{2+}$ concentrations $\geq 700 \mathrm{nM}$ but not at lower diastolic levels of $150 \mathrm{nM}$ and $350 \mathrm{nM}$ as seen with the RyR2-H29D mutation in our study. Intriguingly, the RyR2-S4565R mutation was identified in an infant who died during sleep and not with exertion ${ }^{12}$. Recently, a novel RyR2-R3570W mutation was identified in two index patients with sudden death one while playing volleyball and another while carrying a water bucket ${ }^{27}$. The RyR2-R3570W was found to confer increased channel opening at $350 \mathrm{nM}$ cytosolic $\mathrm{Ca}^{2+}$ concentrations in the non-phosphorylated state. Channel properties at $150 \mathrm{nM} \mathrm{Ca}^{2+}$ concentrations were not reported. The mutation was identified in relatives of these patients who did not exhibit syncope or palpitations, but often had frequent PVCs at rest.

The mechanism by which the H29D single amino acid substitution alters RyR2 channel sensitivity to $\mathrm{Ca}^{2+}$ activation is unclear. The mutation results in an amino acid change from a positively charged to negatively charged residue at the amino terminal cytosolic portion of the ryanodine receptor, which has been identified as a hotspot for pathogenic mutations ${ }^{28,29}$. Based on sequence alignment of the RyR2 protein to the similar RyR1 isoform, the RyR2 H29D mutation might result in an alteration in the loop region between two $\beta$-pleated sheets ( $\beta 1$ and $\beta 2$ ) that form part of the cytoplasmic vestibule of the RyR protein ${ }^{30}$. The histidine at the position 29 in RyR2 primary sequence is conserved among human, rat and mouse. The previously identified CPVT-associated RyR2-A77V mutation is the RyR2 mutation of closest proximity to RyR2-H29D mutation. ${ }^{31}$ Structural studies have shown that the A77V mutation leads to local changes on the surface of RyR2 which may affect domain-domain or protein-protein interactions. ${ }^{32}$ In the case of RyR2-H29D, we can only speculate that the switch from histidine to aspartic acid at position 29 may lead to destabilization of domain or 
protein interactions, leading to a leaky channel. In contrast to CPVT-associated RyR2 mutations, this specific change may confer leakiness in the RyR2 channel in a non-PKA phosphorylated state.

\section{Implications for the clinical management of patients with SC-TdP}

Abnormal RyR2 receptor function among patients with PMVT at rest may be more prevalent than previously thought. Both patients with short-coupled PMVT in our study had syncope while at rest. These data suggest that genetic screening for RyR2 mutations in selected patients with structurally normal hearts and PMVT should not be restricted solely to patients with arrhythmias during exercise. There may be a significant subset of patients with unexplained PMVT or VF who are categorized as having short-coupled torsade de pointes or idiopathic VF who may in fact harbor a RyR2 mutation.

\section{Study limitations}

First, the pedigree of the family in this study is small. We did not have access to extended family members living in India which would have allowed extensive phenotypic and genetic analysis. Second, the etiology of the relatively late age of onset of arrhythmia in both affected individuals with the RyR2-H29D mutation in this study is unclear. While we found that exercise and stress were not arrhythmia triggers in these cases, we were unable to identify other potential triggers. Hence, additional studies to definitively establish a link between novel RyR2 mutations and PMVT at rest are needed through 1) identification of new families with similar phenotypes and RyR2 mutations, 2) creation of a transgenic knock-in mouse model and 3) investigation of human induced pluripotent stem cell-derived cardiomyocytes harboring the RyR2 H29D mutation. Finally, inconsistent early repolarization changes were seen in the two patients who had PMVT and we cannot rule out the possibility of an overlap syndrome involving early repolarization.

\section{Conclusions}

We report a novel mutation in RyR2 linked to short-coupled PMVT at rest. The RyR2H29D mutant channel exhibits unique biophysical properties not seen in previously described CPVT-associated RyR2 mutations: increased sensitivity to diastolic levels of cytosolic $\mathrm{Ca}^{2+}$ as well as a slight decreased binding to the calstabin2 subunit under basal conditions in the absence of PKA phosphorylation. Abnormal ryanodine receptor function may have a role in idiopathic PMVT at rest.

\section{Supplementary Material}

Refer to Web version on PubMed Central for supplementary material.

\section{Acknowledgments}

Funding Sources:

This work was supported by grants from the National Heart, Lung and Blood Institute to Dr. Andrew R. Marks; from the European Society of Cardiology (ESC), from the French Muscular Dystrophy Association (AFM, project 16073, MNM2 2012), and from the FRM (SPF20130526710) to Dr. Albano C. Meli. 


\section{References}

1. Meissner MD, Lehmann MH, Steinman RT, Mosteller RD, Akhtar M, Calkins H, Cannom DS, Epstein AE, Fogoros RN, Liem LB, Marchlinski FE, Myerburg RJ, Veltri EP. Ventricular fibrillation in patients without significant structural heart disease: A multicenter experience with implantable cardioverter-defibrillator therapy. J Am Coll Cardiol. 1993; 21:1406-1412. [PubMed: 8473649]

2. Chen Q, Kirsch GE, Zhang D, Brugada R, Brugada J, Brugada P, Potenza D, Moya A, Borggrefe M, Breithardt G, Ortiz-Lopez R, Wang Z, Antzelevitch C, O'Brien RE, Schulze-Bahr E, Keating MT, Towbin JA, Wang Q. Genetic basis and molecular mechanism for idiopathic ventricular fibrillation. Nature. 1998; 392:293-296. [PubMed: 9521325]

3. Haissaguerre M, Chatel S, Sacher F, Weerasooriya R, Probst V, Loussouarn G, Horlitz M, Liersch R, Schulze-Bahr E, Wilde A, Kaab S, Koster J, Rudy Y, Le Marec H, Schott JJ. Ventricular fibrillation with prominent early repolarization associated with a rare variant of $\mathrm{kcnj} 8 / \mathrm{katp}$ channel. J Cardiovasc Electrophysiol. 2009; 20:93-98. [PubMed: 19120683]

4. Medeiros-Domingo A, Tan BH, Crotti L, Tester DJ, Eckhardt L, Cuoretti A, Kroboth SL, Song C, Zhou Q, Kopp D, Schwartz PJ, Makielski JC, Ackerman MJ. Gain-of-function mutation s4221 in the kcnj8-encoded cardiac k(atp) channel kir6.1 as a pathogenic substrate for $\mathrm{j}$-wave syndromes. Heart Rhythm. 2010; 7:1466-1471. [PubMed: 20558321]

5. Splawski I, Shen J, Timothy KW, Lehmann MH, Priori S, Robinson JL, Moss AJ, Schwartz PJ, Towbin JA, Vincent GM, Keating MT. Spectrum of mutations in long-qt syndrome genes. Kvlqt1, herg, scn5a, kcne1, and kcne2. Circulation. 2000; 102:1178-1185. [PubMed: 10973849]

6. Priori SG, Napolitano C, Tiso N, Memmi M, Vignati G, Bloise R, Sorrentino V, Danieli GA. Mutations in the cardiac ryanodine receptor gene (hryr2) underlie catecholaminergic polymorphic ventricular tachycardia. Circulation. 2001; 103:196-200. [PubMed: 11208676]

7. Leenhardt A, Glaser E, Burguera M, Nurnberg M, Maison-Blanche P, Coumel P. Short-coupled variant of torsade de pointes. A new electrocardiographic entity in the spectrum of idiopathic ventricular tachyarrhythmias. Circulation. 1994; 89:206-215. [PubMed: 8281648]

8. Okin PM, Ameisen O, Kligfield P. A modified treadmill exercise protocol for computer-assisted analysis of the st segment/heart rate slope: Methods and reproducibility. Journal of electrocardiology. 1986; 19:311-318. [PubMed: 3540174]

9. Green, M.; Sambrook, J. Molecular cloning : A laboratory manual. Cold Spring Harbor: Cold Spring Harbor Press; 2012.

10. Lehnart SE, Wehrens XH, Laitinen PJ, Reiken SR, Deng SX, Cheng Z, Landry DW, Kontula K, Swan H, Marks AR. Sudden death in familial polymorphic ventricular tachycardia associated with calcium release channel (ryanodine receptor) leak. Circulation. 2004; 109:3208-3214. [PubMed: 15197150]

11. Meli AC, Refaat MM, Dura M, Reiken S, Wronska A, Wojciak J, Carroll J, Scheinman MM, Marks AR. A novel ryanodine receptor mutation linked to sudden death increases sensitivity to cytosolic calcium. Circ Res. 2011; 109:281-290. [PubMed: 21659649]

12. Tester DJ, Dura M, Carturan E, Reiken S, Wronska A, Marks AR, Ackerman MJ. A mechanism for sudden infant death syndrome (sids): Stress-induced leak via ryanodine receptors. Heart Rhythm. 2007; 4:733-739. [PubMed: 17556193]

13. Wehrens XH, Lehnart SE, Huang F, Vest JA, Reiken SR, Mohler PJ, Sun J, Guatimosim S, Song LS, Rosemblit N, D'Armiento JM, Napolitano C, Memmi M, Priori SG, Lederer WJ, Marks AR. Fkbp12.6 deficiency and defective calcium release channel (ryanodine receptor) function linked to exercise-induced sudden cardiac death. Cell. 2003; 113:829-840. [PubMed: 12837242]

14. Lehnart SE, Mongillo M, Bellinger A, Lindegger N, Chen BX, Hsueh W, Reiken S, Wronska A, Drew LJ, Ward CW, Lederer WJ, Kass RS, Morley G, Marks AR. Leaky ca2+ release channel/ ryanodine receptor 2 causes seizures and sudden cardiac death in mice. J Clin Invest. 2008; 118:2230-2245. [PubMed: 18483626]

15. Brillantes AB, Ondrias K, Scott A, Kobrinsky E, Ondriasova E, Moschella MC, Jayaraman T, Landers M, Ehrlich BE, Marks AR. Stabilization of calcium release channel (ryanodine receptor) function by fk506-binding protein. Cell. 1994; 77:513-523. [PubMed: 7514503] 
16. Xiao RP, Valdivia HH, Bogdanov K, Valdivia C, Lakatta EG, Cheng H. The immunophilin fk506binding protein modulates ca2+ release channel closure in rat heart. J Physiol. 1997; 500:343-354. [PubMed: 9147322]

17. Fauconnier J, Meli AC, Thireau J, Roberge S, Shan J, Sassi Y, Reiken SR, Rauzier JM, Marchand A, Chauvier D, Cassan C, Crozier C, Bideaux P, Lompre AM, Jacotot E, Marks AR, Lacampagne A. Ryanodine receptor leak mediated by caspase- 8 activation leads to left ventricular injury after myocardial ischemia-reperfusion. Proc Natl Acad Sci U S A. 2011; 108:13258-13263. [PubMed: 21788490]

18. Liu X, Betzenhauser MJ, Reiken S, Meli AC, Xie W, Chen BX, Arancio O, Marks AR. Role of leaky neuronal ryanodine receptors in stress- induced cognitive dysfunction. Cell. 2012; 150:1055-1067. [PubMed: 22939628]

19. Leenhardt A, Lucet V, Denjoy I, Grau F, Ngoc DD, Coumel P. Catecholaminergic polymorphic ventricular tachycardia in children. A 7-year follow-up of 21 patients. Circulation. 1995; 91:15121519. [PubMed: 7867192]

20. Haissaguerre M, Extramiana F, Hocini M, Cauchemez B, Jais P, Cabrera JA, Farre J, Leenhardt A, Sanders P, Scavee C, Hsu LF, Weerasooriya R, Shah DC, Frank R, Maury P, Delay M, Garrigue $\mathrm{S}$, Clementy J. Mapping and ablation of ventricular fibrillation associated with long-qt and brugada syndromes. Circulation. 2003; 108:925-928. [PubMed: 12925452]

21. Knecht S, Sacher F, Wright M, Hocini M, Nogami A, Arentz T, Petit B, Franck R, De Chillou C, Lamaison D, Farre J, Lavergne T, Verbeet T, Nault I, Matsuo S, Leroux L, Weerasooriya R, Cauchemez B, Lellouche N, Derval N, Narayan SM, Jais P, Clementy J, Haissaguerre M. Longterm follow-up of idiopathic ventricular fibrillation ablation: A multicenter study. J Am Coll Cardiol. 2009; 54:522-528. [PubMed: 19643313]

22. Kaneshiro T, Naruse Y, Nogami A, Tada H, Yoshida K, Sekiguchi Y, Murakoshi N, Kato Y, Horigome H, Kawamura M, Horie M, Aonuma K. Successful catheter ablation of bidirectional ventricular premature contractions triggering ventricular fibrillation in catecholaminergic polymorphic ventricular tachycardia with ryr2 mutation. Circ Arrhythm Electrophysiol. 2012; 5:e14-e17. [PubMed: 22334434]

23. Lakatta EG. Functional implications of spontaneous sarcoplasmic reticulum ca2+ release in the heart. Cardiovasc Res. 1992; 26:193-214. [PubMed: 1423412]

24. Marban E, Robinson SW, Wier WG. Mechanisms of arrhythmogenic delayed and early afterdepolarizations in ferret ventricular muscle. J Clin Invest. 1986; 78:1185-1192. [PubMed: 3771791]

25. Volders PG, Vos MA, Szabo B, Sipido KR, de Groot SH, Gorgels AP, Wellens HJ, Lazzara R. Progress in the understanding of cardiac early afterdepolarizations and torsades de pointes: Time to revise current concepts. Cardiovasc Res. 2000; 46:376-392. [PubMed: 10912449]

26. Pogwizd SM, Schlotthauer K, Li L, Yuan W, Bers DM. Arrhythmogenesis and contractile dysfunction in heart failure: Roles of sodium-calcium exchange, inward rectifier potassium current, and residual beta-adrenergic responsiveness. Circ Res. 2001; 88:1159-1167. [PubMed: 11397782]

27. Marjamaa A, Laitinen-Forsblom P, Wronska A, Toivonen L, Kontula K, Swan H. Ryanodine receptor (ryr2) mutations in sudden cardiac death: Studies in extended pedigrees and phenotypic characterization in vitro. Int J of Cardiol. 2011; 147:246-252. [PubMed: 19781797]

28. Medeiros-Domingo A, Bhuiyan ZA, Tester DJ, Hofman N, Bikker H, van Tintelen JP, Mannens MM, Wilde AA, Ackerman MJ. The ryr2-encoded ryanodine receptor/calcium release channel in patients diagnosed previously with either catecholaminergic polymorphic ventricular tachycardia or genotype negative, exercise-induced long qt syndrome: A comprehensive open reading frame mutational analysis. J Am Coll Cardiol. 2009; 54:2065-2074. [PubMed: 19926015]

29. Leenhardt A, Denjoy I, Guicheney P. Catecholaminergic polymorphic ventricular tachycardia. Circ Arrhythm Electrophysiol. 2012; 5:1044-1052. [PubMed: 23022705]

30. Tung CC, Lobo PA, Kimlicka L, Van Petegem F. The amino-terminal disease hotspot of ryanodine receptors forms a cytoplasmic vestibule. Nature. 2010; 468:585-588. [PubMed: 21048710]

31. d'Amati G, Bagattin A, Bauce B, Rampazzo A, Autore C, Basso C, King K, Romeo MD, Gallo P, Thiene G, Danielli GA, Nava A. Juvenile sudden death in a family with polymorphic ventricular 
arrhythmias caused by a novel RyR2 gene mutation: evidence of specific morphological substrates. Human Pathology. 2005; 36:761-767. [PubMed: 16084945]

32. Lobo PA, Van Petegem F. Crystal structures of the N-terminal domains of cardiac and skeletal muscle ryanodine receptors: insights into disease mutations. Structure. 2009; 11:1505-1514. [PubMed: 19913485] 


\section{Research Highlights}

- A ryanodine receptor mutation (RyR2-H29D) linked to PMVT at rest is found

- Single channel studies on mutant RyR2-H29D channels and wildtype channels were done

- RyR2-H29D mutant channels have higher open probability under non-stress conditions

- Unlike CPVT-associated RyR2 mutations, RyR2-H29D leads to arrhythmias at rest 
A

I

II

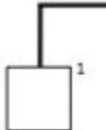

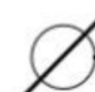
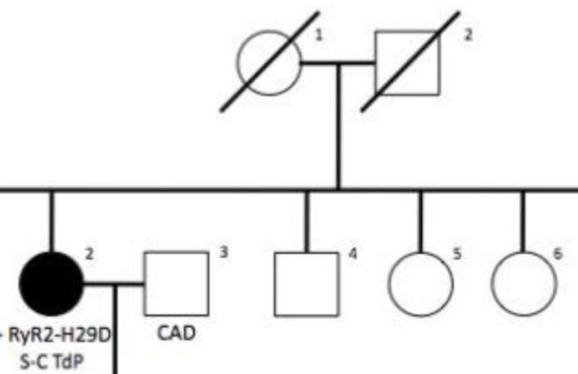

III

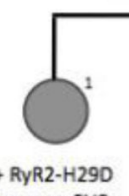

Syncope, PVCs
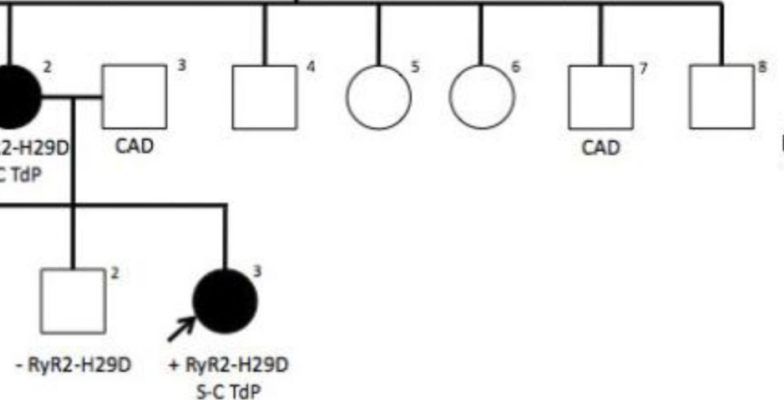

B

H29D

C A $T$ T $C$ C/G A C A A A G

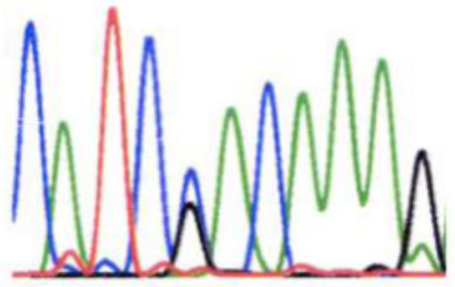

WT
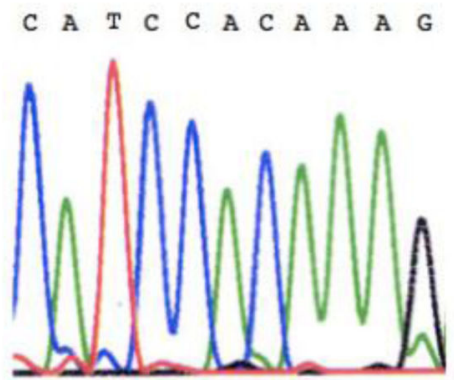

D
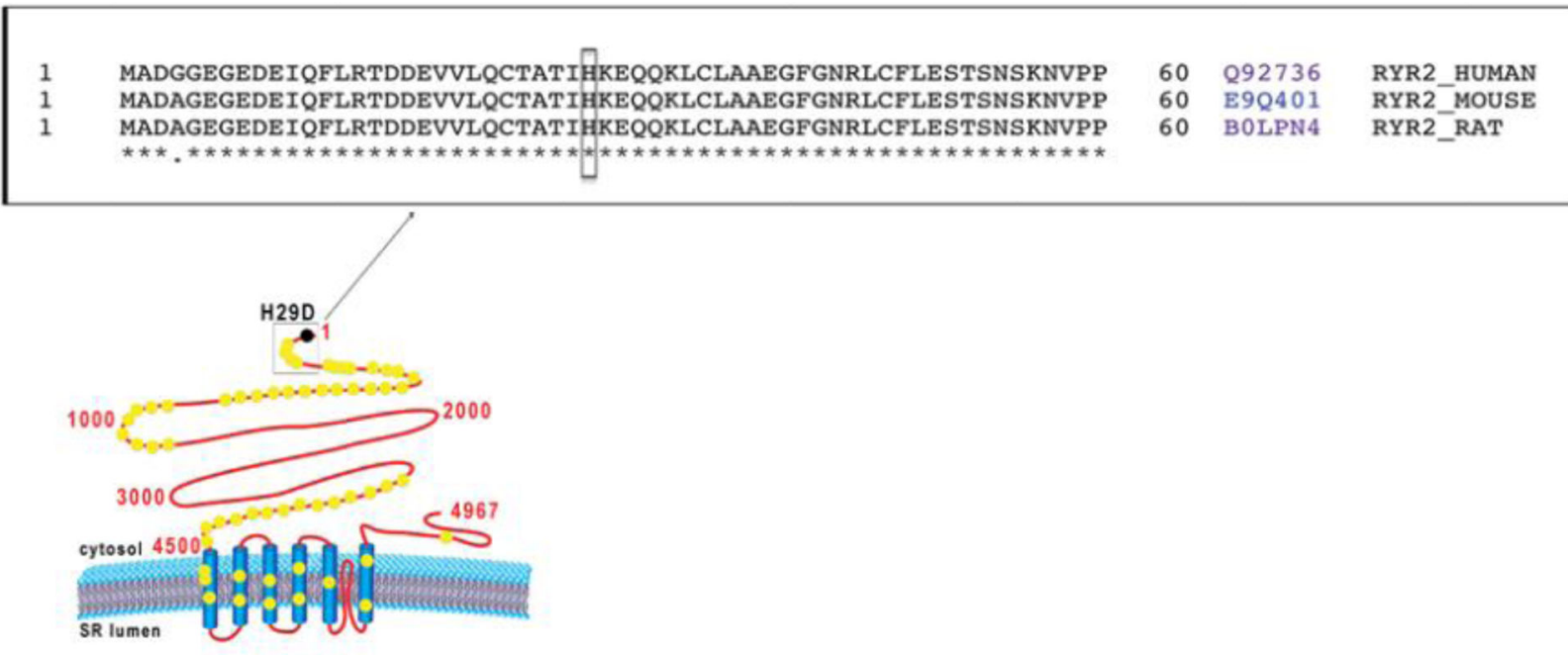

Figure 1.

A: Pedigree of study family. Black symbols denote clinically affected individuals with short-coupled PMVT with proband marked with arrow. Gray symbols denote possibly clinically affected individuals. White symbols denote clinically unaffected individuals. Results of RyR2 genetic screen are marked as positive (+) or negative (-) if performed. B: Results of DNA sequencing of the proband (III-3) demonstrating heterozygous single nucleotide substitution $(\mathrm{C} \rightarrow \mathrm{G})$ at position 85 of the RyR2 gene leading to H29D missense mutation. C: Results of DNA sequencing of the proband's unaffected brother (III-2) 
demonstrating absence of nucleotide substitution at position 85 of the RyR2 gene. D: Schematic diagram of RyR2 displaying putative localization of H29D mutation and known single point mutations (yellow dots) located in hot-spot regions of RyR2. Primary sequence alignment of RyR2, between the position 1 and 60 (boxed) from 3 different species (i.e.

Human \#Q92736, Mouse \#E9Q401, Rat \#B0LPN4) showing conserved (bottom stars) and non-conserved residues (bottom dots). The conserved histidine at position 29 is boxed. Sequence alignment was performed using Uniprot (www.uniprot.org/align). CAD = coronary artery disease; S-C TdP = short coupled torsade de pointes. 


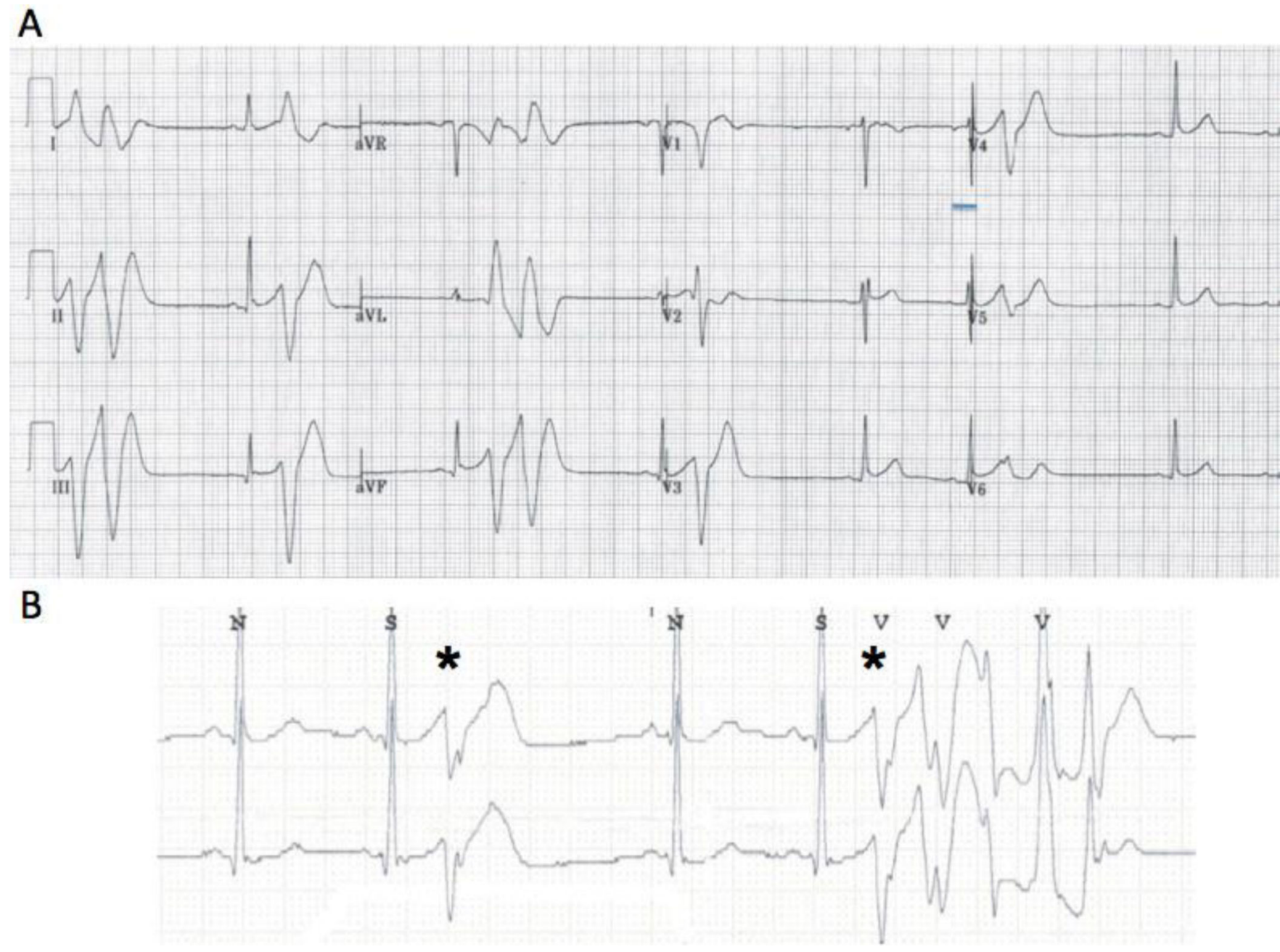

Figure 2.

A: Baseline 12-lead ECG of proband upon presentation with syncope revealing frequent PVCs and couplets. The QTc interval is normal and there is no type I Brugada pattern. Mild early repolarization ( $\leq 0.1 \mathrm{mV}$ ) is seen in leads II, III, aVF and $\mathrm{V}_{2}-\mathrm{V}_{4}$. The left bundle branch block, left superior axis morphology PVCs are short-coupled with a coupling interval of 220-260 ms. B: Telemetry strip revealing frequent PVCs with salvos of nonsustained PMVT. The PVCs (*) have an unifocal morphology with a short coupling interval of 240 ms. 


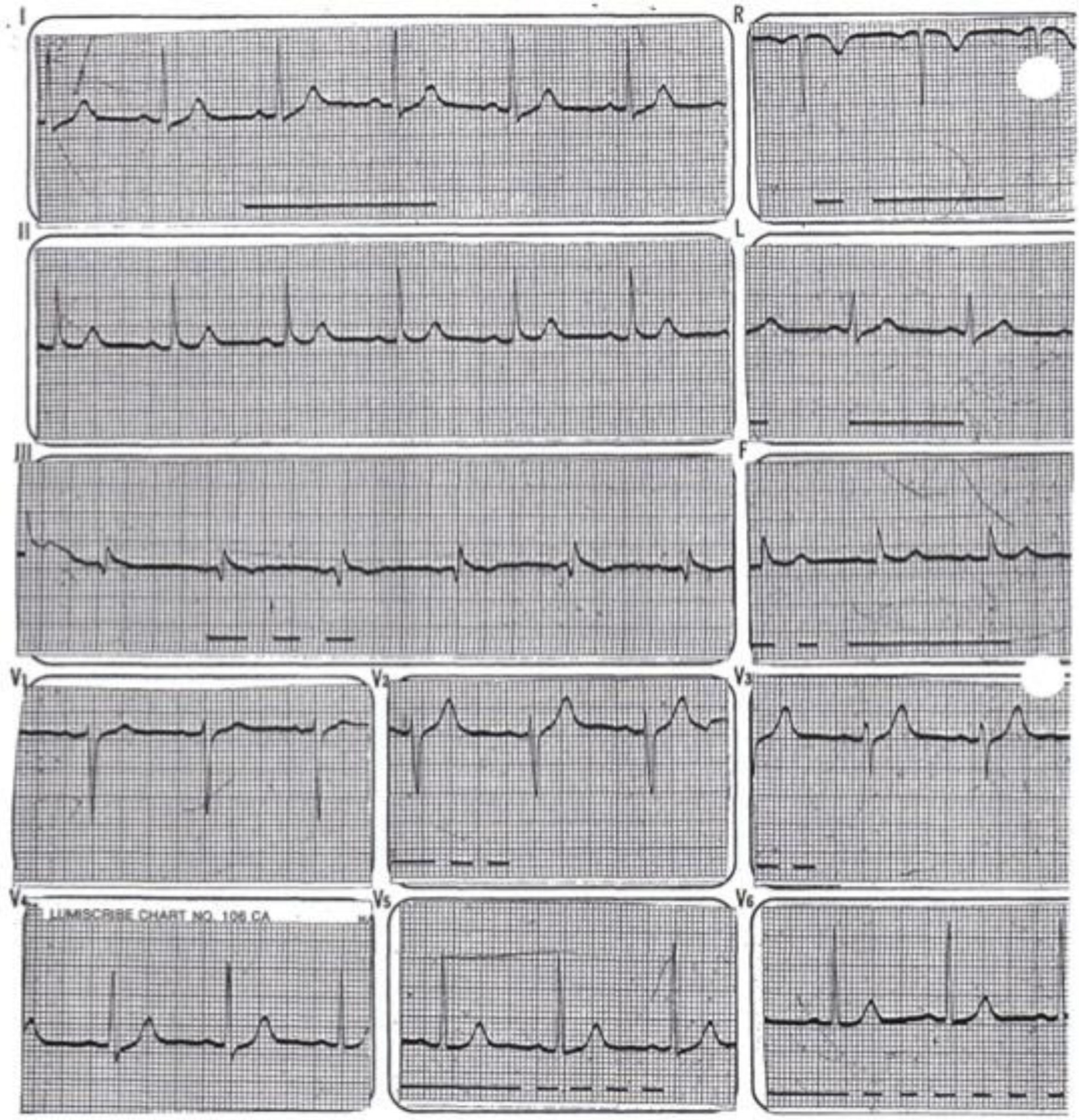




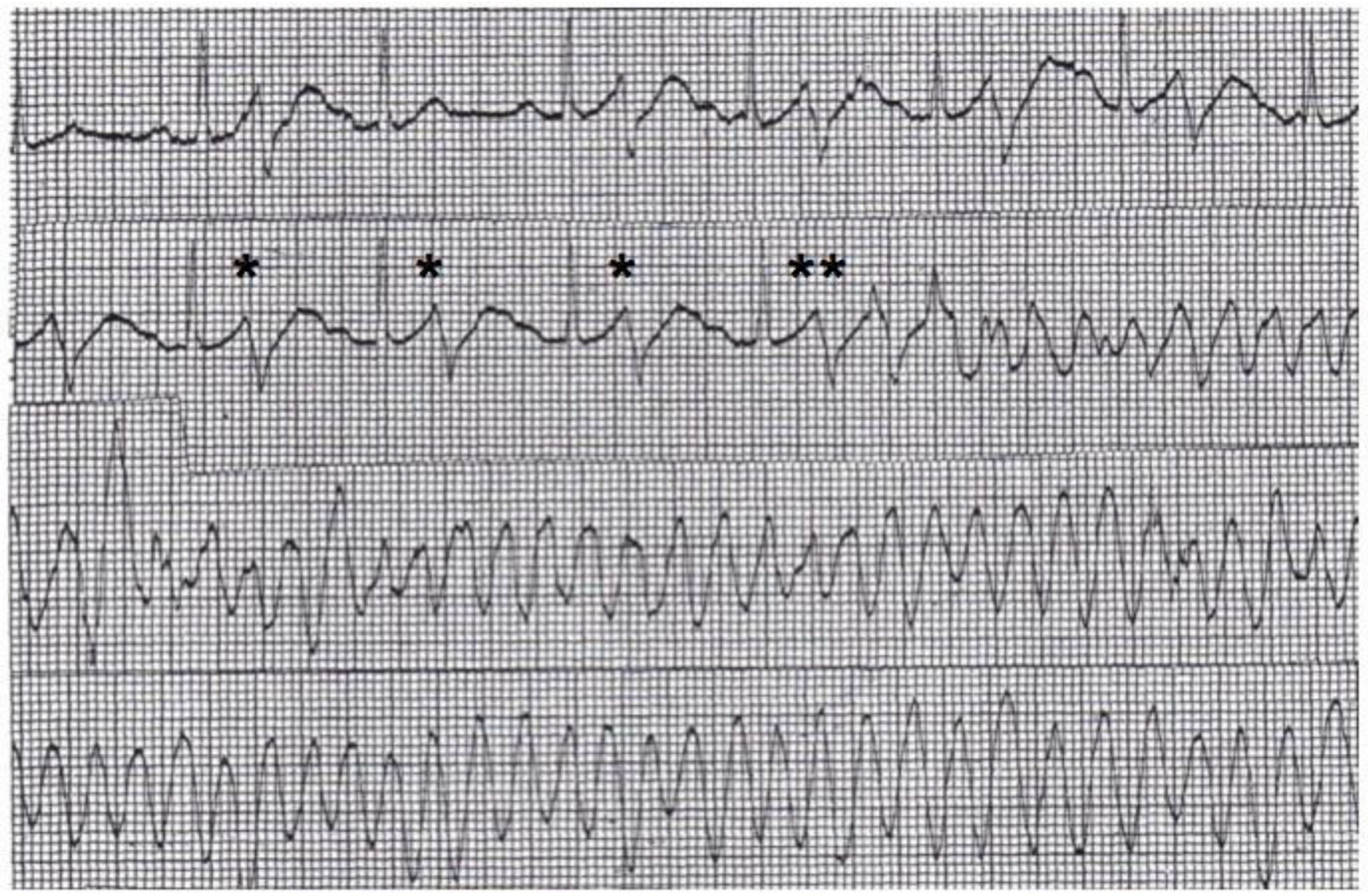

b

Figure 3.

A: Baseline 12 lead ECG of proband's mother revealing normal QT interval and no evidence of Brugada pattern. B: ECG rhythm strip revealing ventricular bigeminy with unifocal PVCs $(*)$ at a short coupling interval of $200 \mathrm{~ms}$. Sustained PMVT is then initiated by the same morphology PVC $(* *)$. 
A

RyR2-WT - $[\mathrm{Ca}]_{\mathrm{cyt}} 150 \mathrm{nM}$
Po 0.01, Fo $22.94 \mathrm{~s}^{-1}$

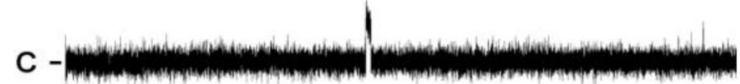

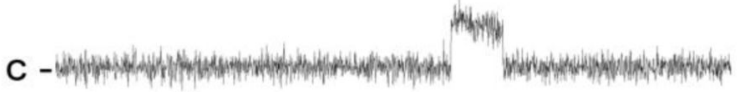

RyR2-WT - [Ca $]_{\text {cyt }} 350 \mathrm{nM}$

Po 0.03 , Fo $68.39 \mathrm{~s}^{-1}$

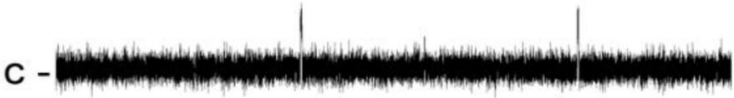

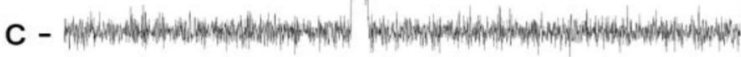

RyR2-WT $+5 \mu$ M ryanodine

c -

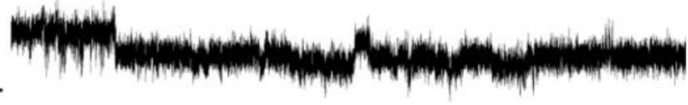

$\left.4 \mathrm{pA}\right|_{1000 / 100 \mathrm{~ms}} ^{\mathrm{C}-}$
B

RyR2-H29D - [Ca $]_{\text {cyt }} 150 \mathrm{nM}$

Po 0.07 , Fo $135.47 \mathrm{~s}^{-1}$

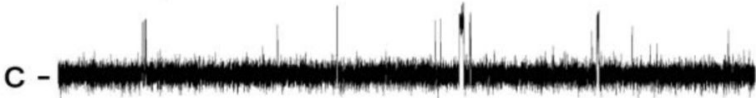

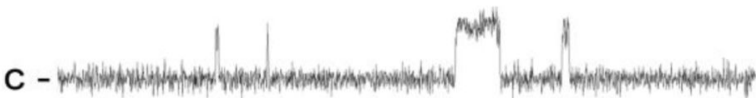

RyR2-H29D - [Ca $]_{c y t} 350$ n M

Po 0.09 , Fo $149.85 \mathrm{~s}^{-1}$

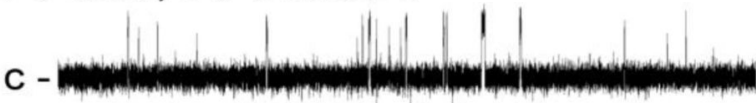

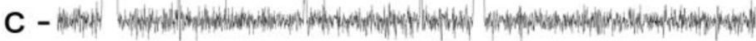

C -
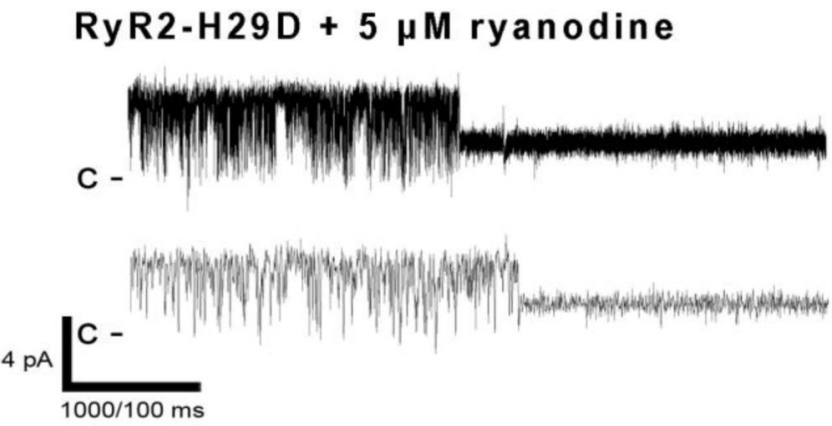

Figure 4. Functional characterization of recombinant human RyR2-H29D mutant

A-B: Representative single channel current traces of RyR2-WT (A) and RyR2-H29D (B) channels measured at 150 and $350 \mathrm{nmol} / \mathrm{L}(\mathrm{nM})$ cytosolic $\left[\mathrm{Ca}^{2+}\right]$. Channel openings are shown as upward deflections; the closed (c-) state of the channel is indicated by horizontal bars in the beginning of each tracing. Specific inhibition at half open state by $5 \mu \mathrm{M}$ ryanodine is displayed for RyR2-WT and RyR2-H29D. Example of channel activity is shown at two different time scales ( $5 \mathrm{~s}$ for one upper trace and $500 \mathrm{~ms}$ for three lower traces) as indicated by dimension bars, and the respective Po and Fo are shown above each 5 s trace. 


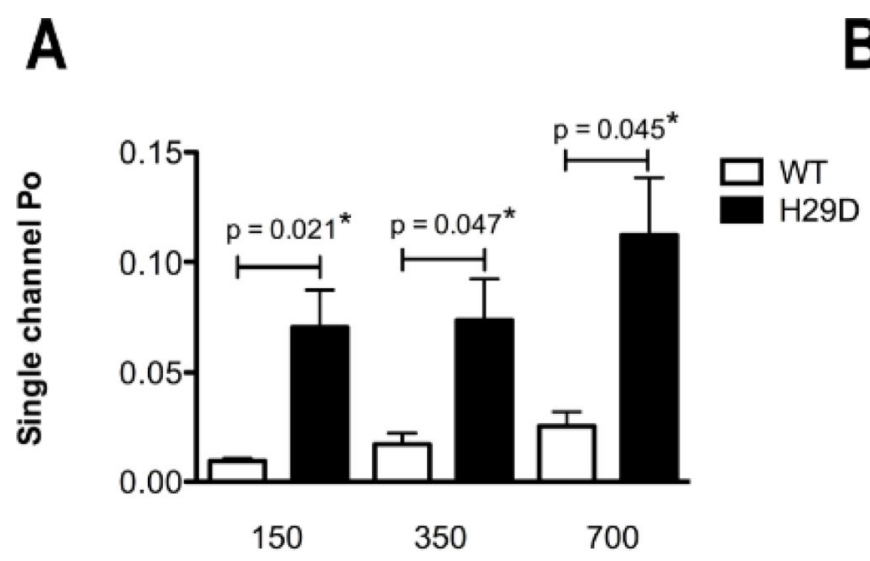

Cytosolic calcium concentration ( $\mathrm{nmol} / \mathrm{L}$ )

C

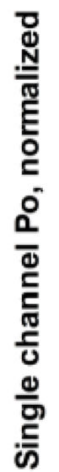

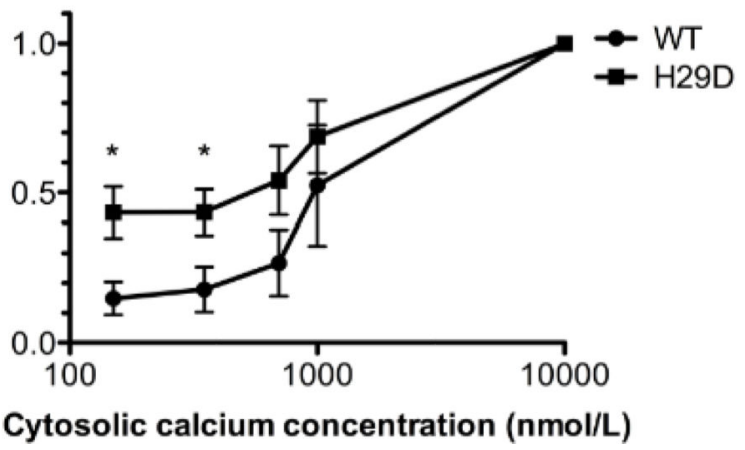

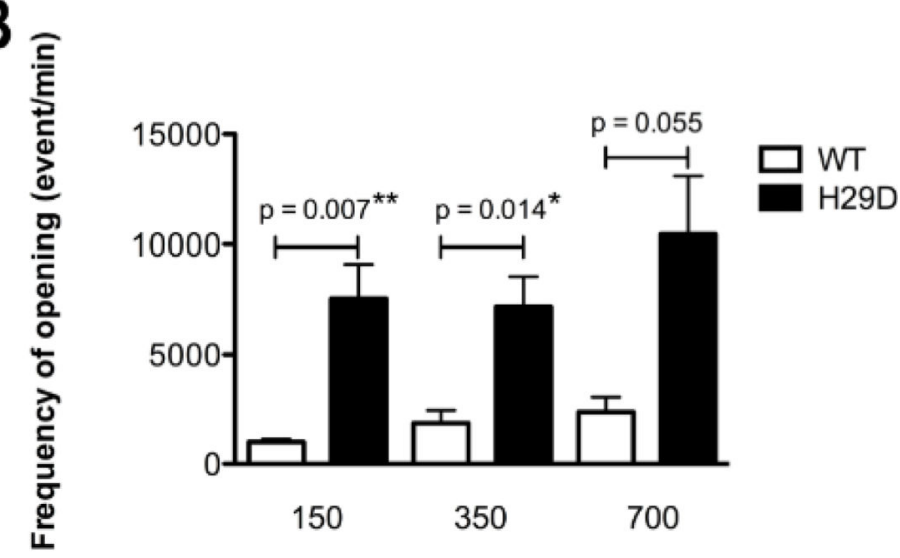

Cytosolic calcium concentration ( $\mathrm{nmol} / \mathrm{L}$ )

Figure 5. Biophysical properties of recombinant human RyR2-H29D mutant

A: Bar graph summarizing single channel Po under 150, 350 and $700 \mathrm{nmol} / \mathrm{L}$ cytosolic $\left[\mathrm{Ca}^{2+}\right]$ in RyR2-WT $(\mathrm{n}=5)$, RyR2-H29D $(\mathrm{n}=11)$ channels. B: Bar graph summarizing the frequency of openings (events/min) under 150,350 and $700 \mathrm{nmol} / \mathrm{L}$ cytosolic $\left[\mathrm{Ca}^{2+}\right]$ in RyR2-WT ( $=5)$, RyR2-H29D ( $=11$ ) channels. C: Normalized single channel open probability of mutant and WT channels were measured at $\mathrm{Ca}^{2+}$ concentrations from 150 $\mathrm{nmol} / \mathrm{L}$ to $10 \mu \mathrm{mol} / \mathrm{L}$. Each data point represents the open probability calculated as an average from 3 to 10 independent experiments and divided by the maximal open probability obtained from $150 \mathrm{nmol} / \mathrm{L}$ to $10 \mu \mathrm{mol} / \mathrm{L}$. Data presented as mean \pm S.E.M; $* \mathrm{p}<0.05 ; * * \mathrm{p}<$ 0.01 . 


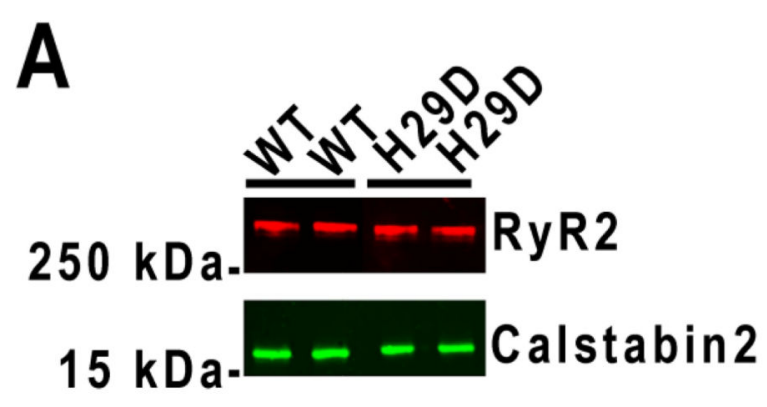

B

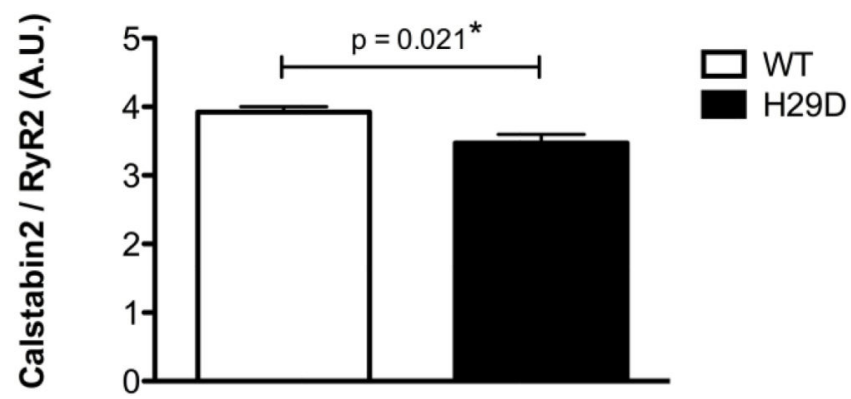

Figure 6. Biochemical characterization of recombinant human RyR2-H29D mutant A: Representative immunoblot of immunoprecipitated recombinant RyR2-WT and RyR2H29D proteins. B: Bar graphs showing amount of calstabin2 (FKBP12.6) immunoprecipitated with RyR2-WT $(n=4)$ and RyR2-H29D $(n=4)$. RyR2 immunoprecipitations were performed on ER vesicles. Antibodies against RyR2 and calstabin2 were used. Levels of calstabin2 in the RyR2 complex were normalized to the total amount of RyR2 (A.U.). Data presented as mean \pm S.E.M.; ${ }^{*}$ p $<0.05$. 


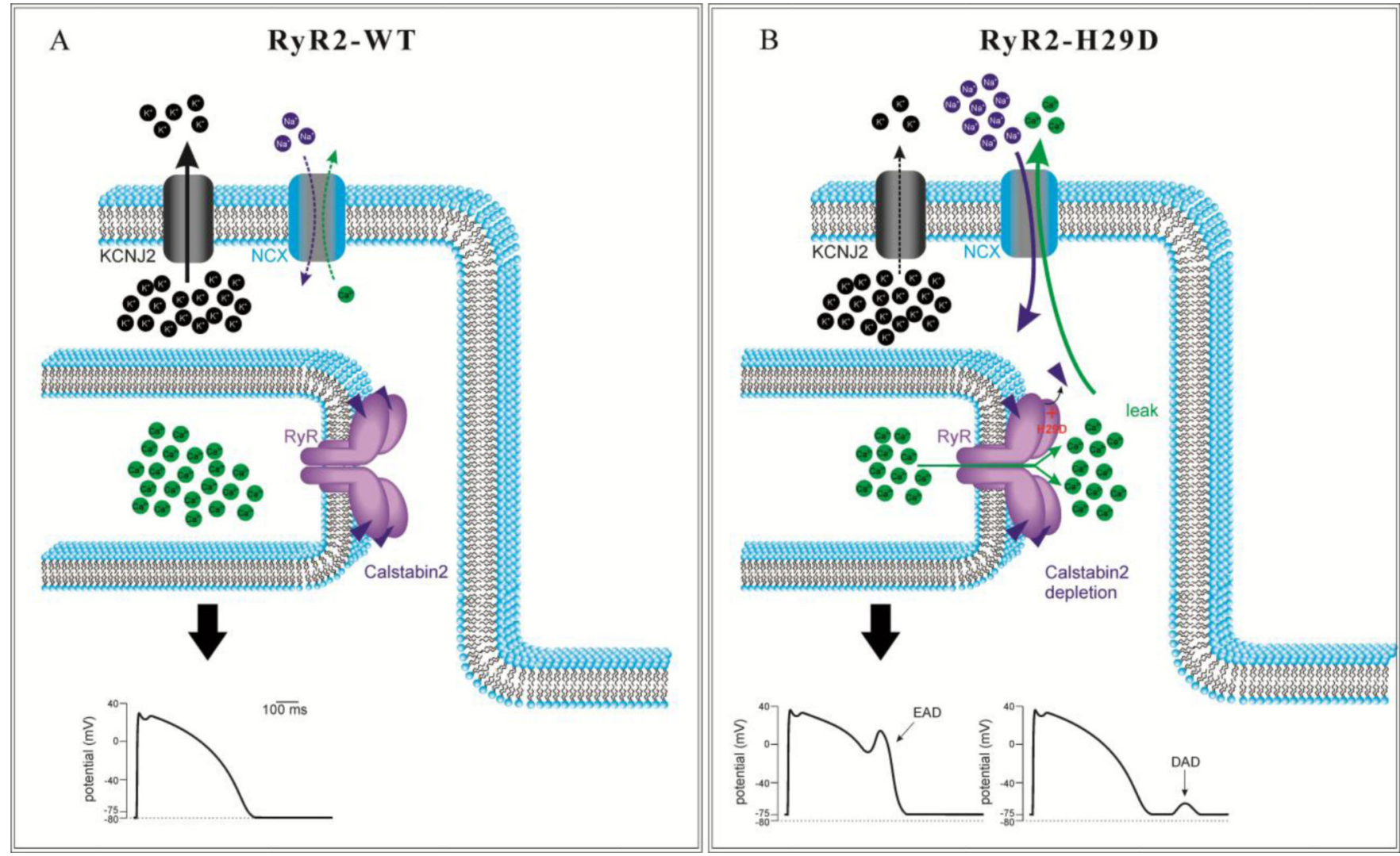

Figure 7. Proposed model of RyR2-H29D mediated $\mathrm{SR} \mathrm{Ca}^{2+}$ leak and arrhythmogenesis A: Schematic diagram depicting normal function of potassium inward rectifier $\mathrm{I}_{\mathrm{K} 1}$ channel (KCNJ2) and $\mathrm{Na}^{+} / \mathrm{Ca}^{2+}$ exchanger (NCX) on plasma membrane and the RyR2-calstabin2 complex on sarcoplasmic reticulum membrane (top) with normal cardiac action potential (bottom). B: Schematic diagram showing potential consequences of leaky RyR2 channels conferred by the RyR2-H29D mutation. Please see Discussion text for details. 